\title{
California cannabis regulation: An overview
}

\author{
In 2016, Proposition 64 decriminalized the possession and use of cannabis by anyone in California \\ aged 21 or over. But the 2015 Medical Marijuana Regulation and Safety Act had begun the process \\ of regulating cannabis in the state.
}

by Robin S. Goldstein and Daniel A. Sumner

$\mathrm{M}$ ore than two decades ago, on November 5, 1996, California voters passed the ballot initiative known as the Compassionate Use Act (Proposition 215). The Compassionate Use Act removed criminal penalties for the possession, use and sale of cannabis for medicinal purposes, thus making California the first U.S. state to decriminalize cannabis since the substance had first been classified by the federal government, in 1970, as a Schedule I narcotic.

By 2019, 36 U.S. states had enacted legislation to remove criminal penalties for the possession and use of medicinal cannabis (the "medicinal decriminalization" of cannabis). In general, medicinal decriminalization means that cannabis can only be sold to customers who obtain a medical doctor's recommendation to use cannabis as a treatment for a state-specified medical condition. In some of the states that have decriminalized medicinal cannabis, only a few specific medical conditions are approved for cannabis treatments; in other states, such as California, there has been little practical restriction on medicinal recommendations.

As of 2019, 10 U.S. states (all of which have decriminalized the medical use of cannabis) have also decriminalized "recreational" or "adult-use" cannabis. The decriminalization of adult-use cannabis in these states means, at a minimum, that a doctor's recommendation is not necessary in order for a state resident or out-ofstate visitor to legally possess and use cannabis.

\section{Adult-use legalization}

In everyday usage, "legalization" has a variety of connotations. The word might refer to the legal possession of cannabis, the legal purchase and sale of cannabis or the reporting of cannabis sales to state-level authorities and those authorities' taxation of cannabis sales. In the United States, common usage of the word "legalization" does not imply that cannabis is legal under federal law. Since the passage of the U.S. Controlled Substances Act of 1970, cannabis has been a Schedule I narcotic. The federal government has approved no medicinal use of tetrahydrocannabinol (THC), the psychoactive component of cannabis. The sale of cannabis remains a felony under federal law.

In California, Proposition 64 - a 2016 ballot initiative known as the Adult Use of Marijuana Act (AUMA) - decriminalized the possession and use of cannabis by any person in California aged 21 or over.

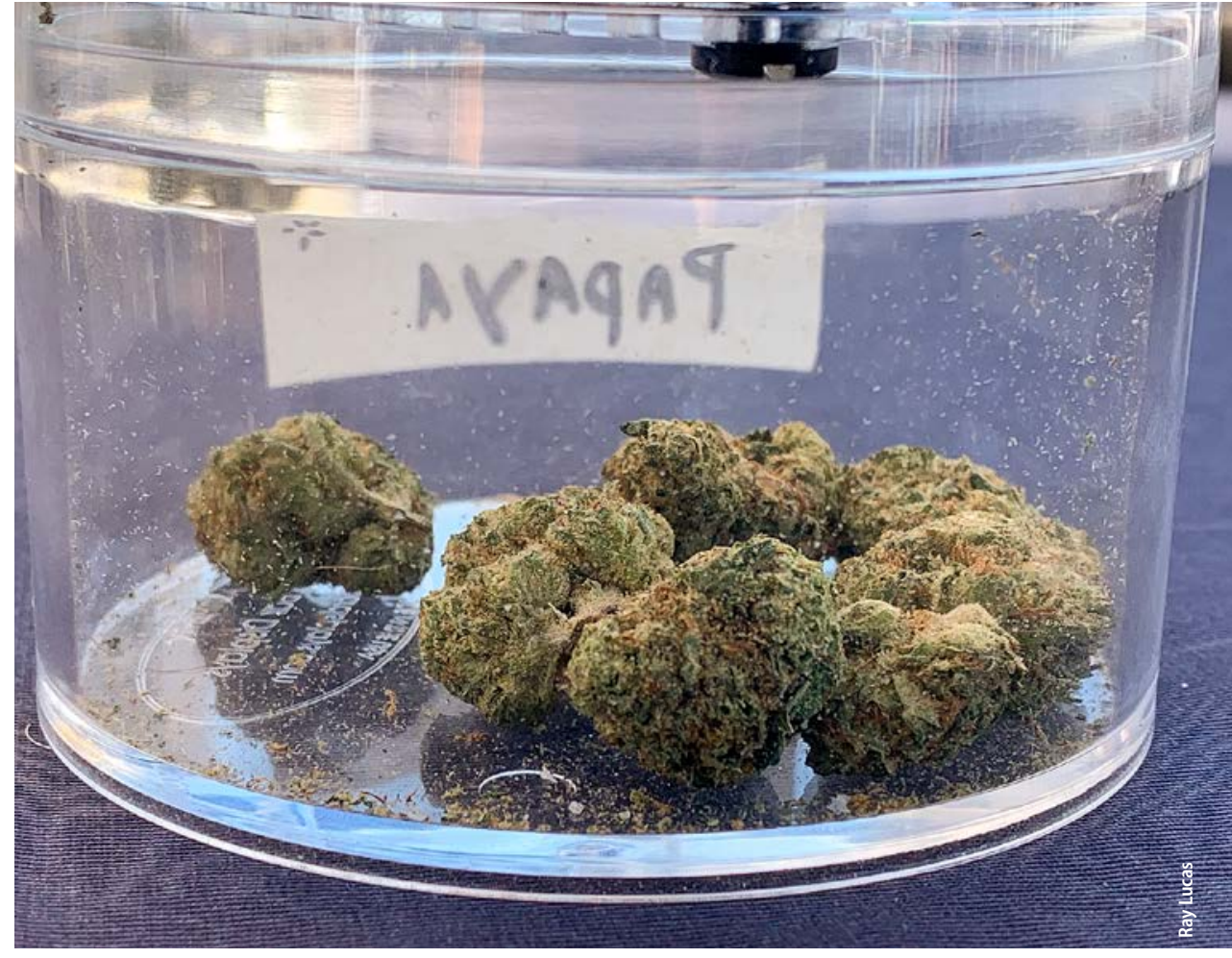

Proposition 64 left in place medical cannabis decriminalization for consumers between 18 and 21 (or below 18 , with a parent or guardian's permission) - and opened a "legal" cannabis market both to state residents without medical recommendations and to visitors from out of state, who under medicinal cannabis law had previously been excluded from buying cannabis through the decriminalized system.

Although Proposition 64 broke down some legal barriers on cannabis sales (especially the ban on selling to non-state residents), it is probably true that, even before the proposition passed, most California residents who wanted to buy cannabis without breaking state laws regarding cannabis possession were able to obtain medical cannabis recommendations with relative ease. By early 2016, for instance, it was possible for a California resident over the age of 18 to receive an official, state-endorsed medicinal cannabis recommendation by simply submitting an online medical form claiming headaches and paying less than $\$ 50$. As of the early fall of 2016, the process of obtaining a medicinal cannabis recommendation for the first time, and then
As of 2019, 10 U.S. states have decriminalized "recreational" or "adult-use" cannabis.
Online: https://doi.org/10.3733/ ca.2019a0021 
using it to order cannabis from a delivery service, could be completed in less than half an hour from start to finish.

\section{Taxation and regulation}

Even before Proposition 64, the 2015 Medical Marijuana Regulation and Safety Act (MMRSA) - which was later extended as the Medicinal and Adult-Use Cannabis Regulation and Safety Act (MAUCRSA) had begun the process of regulating cannabis in California. The law assigns licensing and regulation to three agencies: The Department of Food and Agriculture is responsible for cultivation, the Department of Public Health for manufacturing and the Bureau of Cannabis Control for distribution, testing and retailing (with the bureau, under the Department of Consumer Affairs, designated as the lead agency). Regulations pursuant to the law were initially issued through a series of

The cost of retail cannabis in the legal regulated market is about $50 \%$ higher than it would be without taxes and regulations. emergency and temporary rules. Final regulations came into effect in January of this year (though many licensees continued to operate under temporary licenses). The final regulations, which apply statewide, establish guidelines under which local jurisdictions can (but are not required to) set their own additional taxes and regulations on cannabis businesses.

The regulatory agencies collect license fees from cannabis businesses under their purview. At each stage, the fees range from a few hundred dollars for very small operations up to $\$ 100,000$ or more for largescale cultivators, manufacturers, distributors, testing laboratories and retailers. License fees generate the revenue needed to fund the regulatory apparatus and are generally in the range of $1 \%$ to $2 \%$ of the gross value of output.

Based on specifications in Proposition 64, the state imposes: (1) taxes on sales at the cultivation stage, including a cultivation tax of $\$ 9.25$ per ounce ( $\$ 148$ per pound), on cannabis flower (or dried-flower equivalent) produced and transferred and (2) an excise tax of $15 \%$ on the value of retail cannabis, calculated using a formula that multiplies the actual wholesale price by an assumed retail-to-wholesale price ratio of 1.6. Retail sales of cannabis are also subject to the California state sales tax of $7.25 \%$ and county and city supplemental sales taxes that range from zero to $2.75 \%$. In addition, local governments may apply additional cultivation taxes or assessments, as well as cannabis-specific excise taxes, for which the most common tax rate is about $10 \%$.

Regulations based on specifications in the legislation require that cannabis be tested for potency and product consistency, as well as for pesticides and other contaminants. Regulations specify detailed tests for a wide range of compounds, with low accepted thresholds and tight specifications that are costly to meet. The state's "track-and-trace" system requires cannabis businesses to register the flow of cannabis products through the supply chain to prevent movement of product between licensees and the illegal cannabis supply chain, which continues to operate parallel to the legal industry.

Other important regulations require licensing and background checks, as well as compliance with requirements regarding packaging, labeling, handling, transportation, waste disposal, security, data reporting and hours of operation. It is also important to emphasize that, for many cannabis businesses that had previously operated outside normal legal and regulatory channels, the broad set of environmental, employment and social regulations that covers other farms, manufacturers, wholesalers and retailers was new and unfamiliar. Competitors from the illegal segment of unlicensed businesses, who are not subject to any of these restrictions, continue to grow, process and sell cannabis in a parallel market that still includes many consumers in California.

State-level regulations - from requirements for video security to expensive required testing - also add costs to retail cannabis sold in the legal regulated market. The natural result is that the cost of retail cannabis in the legal regulated market (including compounded taxes and regulatory costs) is about $50 \%$ higher than it would be without the taxes and regulations. Wholesale prices have declined because decriminalization has brought new capital, management procedures and technology to the cannabis industry; likewise, the risks inherent in illegal operations are reduced for compliant operators. Nonetheless, (regulated) retail prices through the first half of 2019 have been higher than the (decriminalized but unregulated) retail prices of 2017, and well above the 2019 prices of cannabis products available in the unlicensed and unregulated market. CA

\section{For further information:}

The first stop for official regulatory and tax information is the California Cannabis Portal at https://cannabis.ca.gov/.

For the required regulatory impact analysis provided by the Bureau of Cannabis Control, see www.dof.ca.gov/Forecasting/Economics/Major_ Regulations/Major_Regulations_Table/documents/DCA_Cannabis_ SRIA_2018.pdf.
R.S. Goldstein is Project Scientist, UC Agricultural Issues Center, where D.A. Sumner is Director. Sumner is also the Frank H. Buck $J$ J. Distinguished Professor in the Department of Agricultural and Resource Economics, UC Davis. 